June 2000 - NREL/CP-550-28533

\title{
Multi-Criteria Decision-Making Process for Buildings
}

\section{Preprint}

\section{J.D. Balcomb and A. Curtner}

To be presented at the American Institute of Aeronautics and Astronautics Conference Las Vegas, Nevada July 24-28, 2000

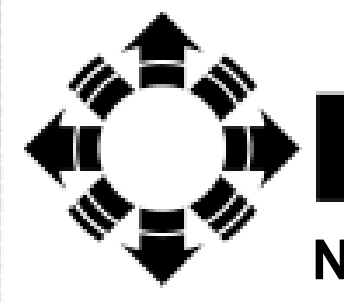

National Renewable Energy Laboratory

1617 Cole Boulevard Golden, Colorado 80401-3393

NREL is a U.S. Department of Energy Laboratory Operated by Midwest Research Institute $\bullet$ Battelle $\bullet$ Bechtel 


\section{NOTICE}

The submitted manuscript has been offered by an employee of the Midwest Research Institute (MRI), a contractor of the US Government under Contract No. DE-AC36-99G010337. Accordingly, the US Government and MRI retain a nonexclusive royalty-free license to publish or reproduce the published form of this contribution, or allow others to do so, for US Government purposes.

This report was prepared as an account of work sponsored by an agency of the United States government. Neither the United States government nor any agency thereof, nor any of their employees, makes any warranty, express or implied, or assumes any legal liability or responsibility for the accuracy, completeness, or usefulness of any information, apparatus, product, or process disclosed, or represents that its use would not infringe privately owned rights. Reference herein to any specific commercial product, process, or service by trade name, trademark, manufacturer, or otherwise does not necessarily constitute or imply its endorsement, recommendation, or favoring by the United States government or any agency thereof. The views and opinions of authors expressed herein do not necessarily state or reflect those of the United States government or any agency thereof.

Available electronically at http://www.doe.gov/bridge

Available for a processing fee to U.S. Department of Energy and its contractors, in paper, from:

U.S. Department of Energy

Office of Scientific and Technical Information

P.O. Box 62

Oak Ridge, TN 37831-0062

phone: 865.576 .8401

fax: 865.576.5728

email: reports@adonis.osti.gov

Available for sale to the public, in paper, from:

U.S. Department of Commerce

National Technical Information Service

5285 Port Royal Road

Springfield, VA 22161

phone: 800.553 .6847

fax: 703.605.6900

email: orders@ntis.fedworld.gov

online ordering: http://www.ntis.gov/ordering.htm

Printed on paper containing at least $50 \%$ wastepaper, including $20 \%$ postconsumer waste 


\title{
MULTI-CRITERIA DECISION-MAKING PROCESS FOR BUILDINGS
}

\author{
Dr. J Douglas Balcomb and Adrianne Curtner \\ National Renewable Energy Laboratory, \\ Golden, Colorado
}

\begin{abstract}
The paper focuses on a process designed to facilitate two key decision points early in the building design process that are critical to a building's ultimate sustainability. As vital decisions are made during the building's design, the process and accompanying tools assist the design team in prioritizing their goals, setting performance targets, and evaluating design options to ensure that the most important issues affecting building sustainability are considered. Both the methods used and the tools required to carry out the methods are described. The process has been conceived to make the most efficient use of both the time and resources of the design team, suggesting that it will actually receive widespread use. The process is being tested within the context of the International Energy Agency Task 23, Optimization of Solar Energy Use in Large Buildings and has also been comprehensively tested by the United States Federal Energy Management Program.
\end{abstract}

\section{INTRODUCTION}

Practicalities of building design require that the design team make very efficient use of its resources and time. This paper recommends a process and describes two computer tools that will aid the design team in ensuring a sustainable design at vital junctures in the design process.

There are two key points early in the building design process in which the ultimate sustainability of the final building is determined. The first is during predesign, when the most important energy-efficient strategies should be selected. The second is during preliminary design, when a choice is made between two or more competing design schemes that have been proposed. The Multi-Criteria Decision-Making (MCDM) process is designed to guide design teams through these stages in a way that makes sustainable building design easy and inexpensive. It facilitates the communication of team priorities, the setting of performance goals, and the evaluation of proposed building designs within the context of the

This paper is declared a work of the U.S. Government and is not subject to copyright protection in the United States. conventional building design process to ensure ultimate building sustainability. The team can avoid the expense of corrections later in the process and be assured that the design will be the most sustainable possible by investing a few hours of time at critical points in the design process.

Early identification of effective energy efficiency measures and building energy use targets is key to sustainable building design. During pre-design, an energy-performance simulation tool can be used to select appropriate strategies. The MCDM process calls for the definition of a reference-case building that identifies how a typical building of the type, size, and location being considered uses energy. The potential for savings is identified by simulating an alternate low-energy case building that incorporates all potential energy-efficiency strategies. An initial selection of strategies is made based on simulating each strategy individually and ranking their effectiveness. Realistic performance targets are set based on these initial results. These performance targets ensure that all proposed designs will achieve a desired level of energy efficiency.

During preliminary design, the team reaches a point where two or more design options have been proposed. Each design incorporates the strategies selected earlier. A decision must be made: which option should be pursued? However, to achieve a design for a building that will be sustainable, the team must consider a multitude of criteria other than energy. A new tool, MCDM-23, automates many of the tasks involved in making an informed selection weighing a broad range of criteria. Inputs to MCDM23 include both quantitative results for each scheme, many of which can be calculated using ENERGY-10, and qualitative results, which can be developed by expert judgement and discussion within the design team. The MCDM-23 program uses a weighting scheme to determine the overall building score based on the results of the qualitative and quantitative evaluations of the proposed building designs. The team develops the weights by expressing their priorities for six criteria (enumerated in Table 2), both quantitative and qualitative, used by the MCDM-23 program. The end products of the program are worksheets and associated diagrams that 
quantify how various design schemes stack up according to the team's criteria.

Advantages of the MCDM-23 program are that it provides an organized framework for decision making and a way to document how the decisions were made. The latter is particularly important in public buildings. One useful product of the procedure is a star diagram, such as the graphic shown on the following page, which identifies how the selected design scheme compares to that of a typical building.

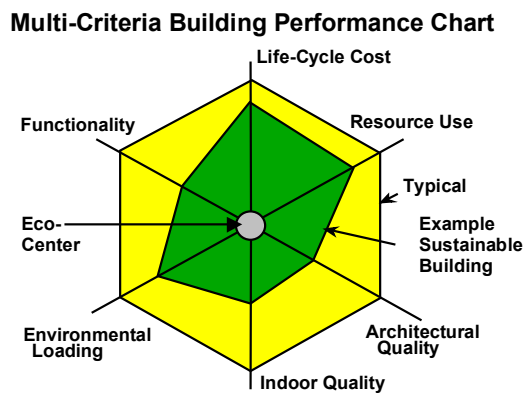

Figure 1: The star diagram is a compact way of displaying the whole picture in one graphic that can be easily interpreted by anyone-architect, engineer, client, energy analyst, building official, reporter, or layman. A smaller footprint is better on this diagram. MCDM-23 automates making this plot based on information derived from the worksheet.

\section{THE DESIGN PROCESS}

Energy efficiency has historically and rightfully been considered the most important building attribute required to achieve a sustainable building. Energy efficiency calls for a whole-building design approach, selecting and integrating those strategies that are most effective in each particular situation. However, to achieve a design for a building that will be sustainable, the design team must consider a multitude of other criteria. Some of these criteria are inherently qualitative in nature and others are amenable to quantitative evaluation.

Given enough time and resources, a design team could sift through the multitude of issues involved in making informed decisions and make the dozens of building simulation calculations required to provide input. Typically, however, resources have not been allocated for any of this work, and only rarely is the design budget increased to accommodate these steps. The only solution to this problem of limited time and resources then is for the design team to make very, very efficient use of them.

The twelve-country International Energy Agency Solar Heating and Cooling Task 23, which concerns Optimization of Solar Energy Use in Large Buildings, has taken on the challenge of recommending a design process and associated design tools for helping design teams to make the most effective use of their time and talent. Their efforts have resulted in the MCDM process, which identifies two critical points in the design process where a small effort can produce big results in terms of building sustainability. Significantly, these points occur very early, when decisions must be made based on very limited information.

For our purposes, the building design process can usefully be divided into four main phases, as shown in Table 1.

Table 1. Four Major Steps in the Building Design Process

\begin{tabular}{ll}
\hline Working Name & Other Names Used \\
\hline Pre-design & $\begin{array}{l}\text { Programming } \\
\text { Strategic Planning } \\
\text { Pre-Project } \\
\text { Investigation of Basics }\end{array}$ \\
& Schematic Design \\
& $\begin{array}{l}\text { Preliminary Studies } \\
\text { Preliminary Design }\end{array}$ \\
& Project \\
& Preparation of Realization \\
& Definitive Proposal \\
Design Development & Building Documents \\
& Realization
\end{tabular}

Chances are that any one practitioner will be used to different terms. We needn't belabor the precise definition of these steps, only acknowledge the importance of early phases, especially the first two. Usually the steps are defined contractually between the design team and the client, making it expensive and difficult to undo decisions made in a previous step during a later step. This puts a high premium on making correct decisions early and on making decisions efficiently based on information available at the time.

\section{THE RIGHT INFORMATION AT THE RIGHT TIME}

The first critical juncture in the design process is the transition from pre-design to preliminary design. The most efficient use of the designer's talents will be made if they can proceed with the design with many decisions that affect energy efficiency and sustainability having already been made. This sounds impossible, but in fact it is quite simple, given the right tool. Most building attributes required to achieve energy efficiency and sustainability have little or nothing to do with the details of building geometry. Those issues that are affected by geometry 
can be dealt with through straightforward means. Many critical decisions can truly be made before design starts.

An energy analyst makes some preliminary calculations, then presents the results to the designers, who can proceed confidently into preliminary design with better information. Similarly, the MCDM process facilitates the discussion of many other aspects that affect sustainability. With a clear understanding of the priorities of the design team and other stakeholders, the designers can address all important issues at the start. Not only dos the MCDM process set performance goals and energyuse targets, it helps to identify effective design strategies through which the goals may be realized, leaving the designers relieved to be able to focus on other issues. It may be necessary to re-affirm some decisions later, but the work will be significantly reduced.

The second critical juncture occurs toward the end of preliminary design. During the preliminary design phase, the designers typically develop two or more design options, which we will call schemes. Because the designers were informed by the results of the predesign energy and sustainability evaluations, many key decisions will have already been made. As a result, each scheme will likely perform quite well on both accounts. Ideally, each scheme will meet the performance targets set earlier. However, the selection of energy design schemes is also dependent on factors other than energy performance and sustainability. Thus, another type of tool, in addition to the energy-analysis tool used in pre-design, may be used to facilitate the decision process at this point. The tool required at this juncture is one that facilitates multi-criteria decision-making, and the comparison of dissimilar criteria.

The MCDM process is very efficient. Decisions are made early enough and quickly enough that backtracking is avoided. All that is left to the end of the design process is to confirm that performance requirements have been met.

\section{$\underline{\text { THE TOOLS }}$}

There are two tools required to facilitate this process.

1. The first tool is an hour-by-hour energyperformance simulation program that has been programmed to automate the several steps required. The tool being used in Task 23 is ENERGY-10, a design tool developed at the National Renewable Energy Laboratory (NREL) and widely used in the United States. This tool, while it does not incorporate all the features desired, does enough to serve as a useful prototype. The evaluations done by ENERGY -10 are sufficiently comprehensive to capture the subtle interactions between the various energyefficient strategies to produce accurate results.

2. The second tool automates the several steps involved in using the MCDM procedure being developed within Task 23. The end products of the program are worksheets and associated star diagrams that quantify how two or more design schemes stack up according to six main criteria that have been selected by the Task 23 group. The tool is a computer program called MCDM23 and was developed at the National Renewable Energy Laboratory specifically for Task 23. It can easily be modified as the requirements of Task 23 evolve.

The MCDM-23 program does not reduce the building design process to a prescriptive procedure. Rather, it provides a framework within which to carry out the several tasks inherent in a partly qualitative decisionmaking process. It facilitates rather than dictates. The eight key steps are: (1) determine weights and subweights for qualitative and quantitative criteria by expressing team priorities, (2) evaluate a reference building and enter scores, (3) consider two or more design schemes, (4) calculate scores for quantitative criteria, (5) determine scores for qualitative criteria, (6) enter scores for each scheme, (7) print a worksheet and star diagram for each scheme, and (8) select the winning scheme. ENERGY-10 has been described extensively and need not be discussed further here. ${ }^{1,2}$ This paper describes the MCDM-23 tool. Before beginning, however, it is important to introduce an important concept, the reference-case building.

\section{THE REFERENCE BUILDING}

The fact that there is no design to evaluate during the pre-design phase actually makes life easier, not more difficult. A very useful procedure is to identify a simple rectangular building geometry that has the principal attributes of the building being designed (1) it is in the same location (weather characteristics), (2) it is of the same size (floor area), and (3) it fits the same building-use category (occupancy characteristics). There may be other constraints defined at the beginning by the site or other preconditions, such as the number of stories, the building orientation, or the choice of heating, ventilating, and air-conditioning (HVAC) equipment. If not predetermined, these can be defaulted.

This rectangular building, which we will call a reference building, can be evaluated quite easily. The 
geometry is simple. Unknown characteristics can be defaulted to typical construction practice in the locality or to conform to prescriptive code regulations. The resulting building serves a very useful purpose: it is an initial benchmark. Subsequently, the design team may choose to redefine the benchmark building (often called a basecase); however, it is better at the beginning to keep the reference building as simple as possible. The reference building serves purposes beyond predesign.

\section{DECISION MAKING IN THE PRE-DESIGN PHASE}

Decision-making in the Pre-Design Phase involves articulating design team priorities and selecting building energy performance goals. The MCDM process spans the pre-design and preliminary design portions of a building project.

\section{Building Energy Use Performance Targets}

A few key simulation results are most informative for setting performance goals during pre-design. These calculations need to be made quickly. The critical steps are:

1. Evaluate the reference building. An hour-by-hour simulation is done based on a typical reference year of weather data for the locality. Occupancy characteristics and energy load profiles are matched as closely as possible to building use.

2. Create an alternate building, which we will call a low-energy case. This is done by globally modifying the reference building description to affect the application of a set of energy-efficient strategies. The basic building geometry is not changed. The strategies might include: daylighting with associated dimming of artificial lights, energy-efficient lights, improved insulation throughout, improved windows, reduced infiltration, passive solar heating, shading windows, adding thermal mass, higher efficiency HVAC, relocation of ducts inside the thermal envelope, improved HVAC controls, and using an economizer cycle. It is better to be inclusive rather than exclusive and to apply each strategy aggressively.

3. Evaluate the low-energy case building. Although the identification of strategies and the degree to which they are applied might have been arbitrary, the aggregate result of applying all of them will result in a useful second benchmark. The result may appear as shown in Figure 2. This shows the potential for improvement, not taking into account improvements that may result from changes to the building geometry.

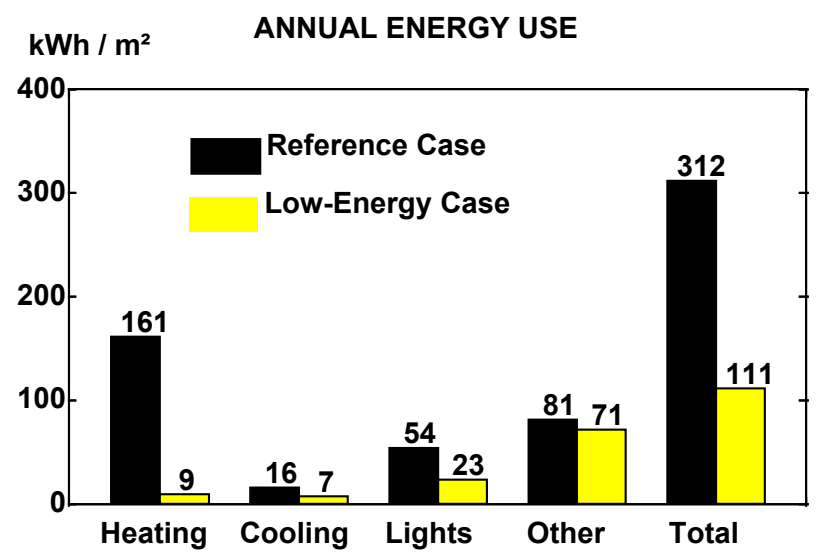

Figure 2: Simulation results for an office building in Cambridge, England. Twelve energy efficiency strategies were applied to the reference case to create the low-energy case building. Both are $18 \times 55 \mathrm{~m}\left(1000 \mathrm{~m}^{2}\right)$ one-story with east-west major axes.

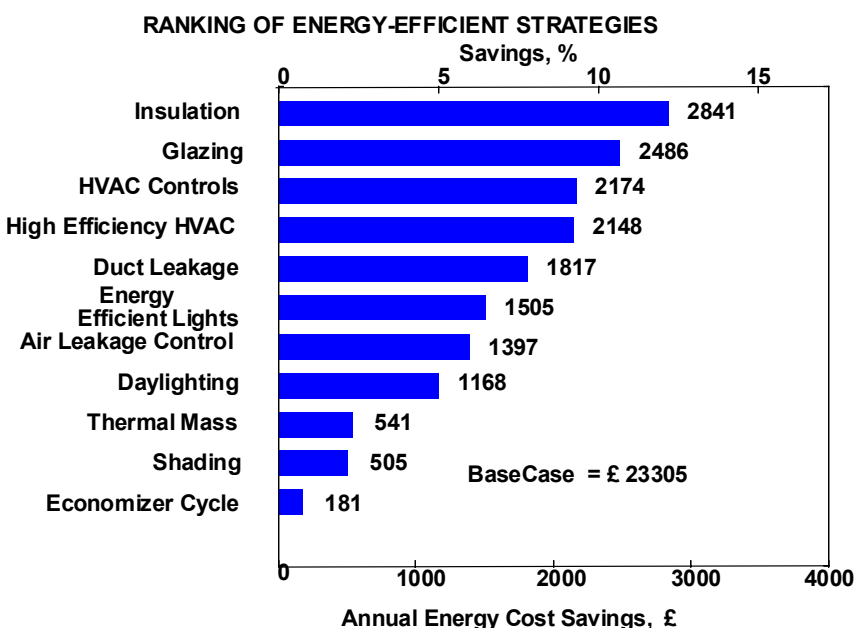

Figure 3: Ranking of strategies for the building shown in Figure 2. Each strategy was applied individually, simulated, and the results were saved. The graph shows the results sorted according to energy savings. Note that many strategies are important. On the basis of this ranking, one might choose the top eight strategies.

4. Add each strategy individually to the reference building and evaluate. Repeat for all strategies. Rank the strategies by some criteria, such as energy savings, reduction in operating cost, or reduction in life-cycle cost. The result may appear as shown in Figure 3. This serves to identify the most effective strategies and facilitates an initial screening. Because of 
interactions between the strategies, the sum of all the individual savings will likely be greater than the total realized in step \#3.

5. Re-create the low-energy case building applying only the most effective strategies. Evaluate this building. The result won't be very different from the result in step $\# 3$, because only the leasteffective strategies were discarded.

6. Based on the result of step \#5, select one or more performance targets for the project. This could be stated in terms of either energy or operating cost. For example, the target for the Cambridge office might be set at $120 \mathrm{kWh} / \mathrm{m}^{2}$. This is both aggressive and clearly achievable.

This process, which can be carried out in less than a half-hour, serves several purposes. The computed reference case building energy use clearly identifies how a typical building of this type and size operates. The potential for savings is identified by the results of the low-energy case. An indication of which strategies will be most profitably pursued is made, and realistic performance targets are set. Additionally, defining a reference case and corresponding lowenergy case building sets a standard and scale by which actual concepts may be judged. The importance of this will become more evident later in this paper.

Because a simple rectangular geometry was used, some may suspect that the strategies identified by this procedure will be different than those that would be identified using the final building geometry. Experience shows that this is not the case. Strategies that were marginal may change, but the selection of the major strategies is very unlikely to differ.

A key advantage of this procedure is that it makes very efficient use of the time of both the designers and the energy analysts. The calculations can be done very quickly - perhaps 10 or even 100 times more quickly than if they were done on a complex geometry because of the inherent difficulty of describing and continually modifying the building description. In reality, the chances that a comprehensive differential evaluation will be carried out are very small unless it is done at the very beginning. It is very time-consuming and expensive to do it later.

Daylighting performance, of course, depends critically on the details of building geometry. The purpose of the daylighting calculation based on the rectangular geometry is not to simulate the final design but to identify the potential for daylighting to save energy. This can be done with a simple geometry in which daylighting is done by windows and skylights, preferably with a geometry that is thin enough to provide adequate side-lighting of lower levels.

If daylighting is one of the strategies selected in predesign, then the burden rests on the designers to develop building designs that will achieve roughly the same degree of dimming (or greater). Preferably, this will be accomplished using sophisticated daylighting strategies such as light shelves, roof monitors, and clerestories that will achieve wellbalanced lighting throughout the building, helping the building to score well in all categories.

\section{Other Building Performance Issues}

The MCDM process facilitates not only the determination of an energy performance goal, but also of other goals relating to building sustainability. Design team members meet to determine the group priorities as defined within the framework of the MCDM-23 program. The group priorities are expressed as weights within this program.

In MCDM-23, six major criteria (enumerated in Table 2) are identified. The selection of criteria was accomplished within the International Energy Agency (IEA) Task-23 group, which includes a mix of 25 highly knowledgeable and experienced designers, engineers, and analysts. These criteria can be important for all building projects, however, the most important criteria may vary from project to project. The MCDM-23 tool therefore offers the possibility to change or exclude some of the criteria. The criteria and sub-criteria default weights are shown in Table 2. The default weights indicate relative priorities. For example, the defaults for the main criteria weights are all set to be equal, indicating that each of these criteria are considered equally. This is merely a default and will preferably be changed by individual design teams.

In Table 2, there are two different types of weights listed. The first are the coefficients for the scores given to the six main criteria. The second weights, called sub-weights, are the coefficients that multiply the raw building scores determined from evaluating the designs. Multiplying the raw building design scores by their sub-weights and adding all weighted sub-scores within a criteria category gives the overall score for that category. Each of the overall category scores are then multiplied by their respective weights and are aggregated to form the overall building score.

The design team determines the main criteria weights by prioritizing the six main criteria used by the 
MCDM-23 program. Team members indicate the relative importance of criteria by evaluating pairs of criteria. This is achieved by answering such questions as: "On a scale of 1 to 10 , how do life cycle cost and resource use compare to each other in importance? (Here, 1 means that resource use is totally important, 5 means that resource use and life cycle cost are of equal importance, and 10 means that life cycle cost is totally important.) This process is repeated to determine weights for the sub-criteria for architectural quality, indoor quality, and functionality. For the quantitative criteria: life-cycle cost, resource use, and environmental loading, the sub-weights can be calculated. In the case of lifecycle cost, the program incorporates the life-cycle cost equations; the user enters the relevant financial parameters (e.g. discount rate, building lifetime, mortgage interest, etc.) and the program calculates the three weights (coefficients).

The MCDM-23 program then uses a statistical method called the Analytical Hierarchy Process to assign weights to each criteria based on the team's answers to the criteria-pairing questions. By determining these weights prior to beginning the building design, the team arrives at mutual conclusions about which goals should receive priority in the design process. This consensus about design priorities is a great help to designers.

The design team will probably not agree on these criteria and weights. However, the weights can all be changed and the names of the sub-criteria under architectural quality and functionality can all be changed to better reflect the team's perspectives. With this flexibility, the choice of criteria should be acceptable to most teams. Gaining acceptance at the beginning is very important.

\section{DECISION MAKING DURING THE PRELIMINARY DESIGN PHASE}

Typically, the team reaches a point in the preliminary phase of the design process where two or more design options have been proposed and a decision must be made. Incidentally, a similar situation is reached in a design competition, where a jury must choose between alternative design proposals. The purpose of MCDM-23 is to facilitate making the best decision.

The five steps in using MCDM-23 during the preliminary design phase are as follows:

1. The design team determines their preferences for the relative importance of the six main criteria as described above. (This actually occurs in the pre-design phase, immediately before the design work commences, but is an inherent part of using the MCDM-23 program.)

2. The energy analyst enters performance values of the reference case into the MCDM-23 program. The energy,

Table 2. Selection Criteria

\begin{tabular}{|c|c|c|c|}
\hline Criteria & Default Main Weight & Sub-Criteria & Default Sub-Weight \\
\hline \multirow[t]{3}{*}{ Life cycle cost } & $1 / 6$ & Construction cost & .68 \\
\hline & & Annual operation cost & 19.4 \\
\hline & & Annual maintenance cost & 19.4 \\
\hline \multirow[t]{5}{*}{ Resource use } & $1 / 6$ & Annual electricity, $\mathrm{kWh} / \mathrm{m}^{2}$ & 3 \\
\hline & & Annual fuels, $\mathrm{kWh} / \mathrm{m}^{2}$ (of heat equivalent) & 1 \\
\hline & & Annual water, $\mathrm{kg} / \mathrm{m}^{2}$ & 0.15 \\
\hline & & Construction materials, $\mathrm{kg} / \mathrm{m}^{2}$ & 0.03 \\
\hline & & Land, $\mathrm{m}^{2} / \mathrm{m}^{2}$ & 300 \\
\hline \multirow[t]{6}{*}{ Environmental loading } & $1 / 6$ & $\mathrm{CO}_{2}$-emissions from construction, $\mathrm{kg} / \mathrm{m}^{2}$ & 1 \\
\hline & & $\mathrm{SO}_{2}$-emissions from construction, $\mathrm{kg} / \mathrm{m}^{2}$ & 90 \\
\hline & & $\mathrm{NO}_{\mathrm{x}}$ emissions from construction, $\mathrm{kg} / \mathrm{m}^{2}$ & 45 \\
\hline & & Annual $\mathrm{CO}_{2}$ emissions from operation, $\mathrm{kg} / \mathrm{m}^{2}$ & 30 \\
\hline & & Annual $\mathrm{SO}_{2}$ emissions from operation, $\mathrm{kg} / \mathrm{m}^{2}$ & 3000 \\
\hline & & Annual $\mathrm{NO}_{\mathrm{x}}$ emissions from operation, $\mathrm{kg} / \mathrm{m}^{2}$ & 1500 \\
\hline \multirow{4}{*}{ Architectural quality } & $1 / 6$ & Identity & 0.25 \\
\hline & & Scale/proportion & 0.25 \\
\hline & & Integrity/coherence & 0.25 \\
\hline & & Integration in urban context & 0.25 \\
\hline \multirow[t]{4}{*}{ Indoor quality } & $1 / 6$ & Air quality & 0.35 \\
\hline & & Lighting quality & 0.25 \\
\hline & & Thermal quality & 0.20 \\
\hline & & Acoustic quality & 0.20 \\
\hline \multirow[t]{4}{*}{ Functionality } & $1 / 6$ & Functionality & 0.45 \\
\hline & & Flexibility & 0.15 \\
\hline & & Maintainability & 0.25 \\
\hline & & Public relations value & 0.15 \\
\hline
\end{tabular}


operating cost, and environmental loading associated with operation have already been calculated using ENERGY-10. The added construction cost is zero by definition. Scores for the qualitative criteria are usually all $5 \mathrm{~s}$ (indicating typical performance).

3. The energy analyst calculates the performance of each of the schemes being proposed and enters these numbers into the MCDM-23 program.

4. The design team determines the scores for the qualitative criteria using the 0 -to-10 scale, and the results are entered into the MCDM-23 program.

5. Worksheets and star diagrams are printed, and the team studies these to make their recommendations to the client.

The MCDM-23 program results rely on three key concepts. One is that building energy performance is determined relative to the performance of the reference case building, which has already been defined. This provides a scale for quantifying performance. The second concept is that the relative score is linear*. If the performance metric of a particular criteria is $20 \%$ better than the corresponding score of the reference case building, then the relative score is $20 \%$ better.

The third concept is that the criteria weights are used as scaling factors to relate the scores on one criterion to the scores on all other criteria. This makes it possible to aggregate all the scores and the weights into an overall measure of goodness. The weights define acceptable trade-offs between criteria; thus, they are related to the scales on which the attributes are defined. Hence, if criterion A has a weight that is twice that of criterion $\mathrm{B}$, this should be interpreted that the decision makers value 10 points on the scale for criterion A the same as 20 points on criterion B and would be willing to trade one for the other. Put another way, the decision makers should be indifferent to a trade between 1 unit of $\mathrm{A}$ and 2 units of B.

Two scoring scales are used in the MCDM-23 process. A scale of 0 to 10 is used for those criteria for which it is conventional to think in terms of

\footnotetext{
* It would not be at all difficult to modify the linearity assumption. An advantage would be that the increasing difficulty and cost of achieving greater and greater performance gains could be more accurately accounted. This would require some minor re-programming in MCDM-23. Appropriate nonlinear algorithms would need to be defined and agreed upon.
}

"bigger is better". In this case, 0 is the minimum acceptable, 10 is the maximum achievable, and 5 is typical. These criteria are architectural quality, indoor quality, and functionality.

A scale of 0 to 2 is used for those criteria for which "smaller is better". For this scale, 0 is the maximum achievable, 2 is the minimum acceptable, and 1 is typical. These criteria are life-cycle cost, resource use, and environmental loading. Any confusion or ambiguity introduced by the use of two scales is more than offset by the convenience introduced by using an appropriate scale for each criteria. The two scales can be readily mapped one to the other. The mapping is a simple linear transformation.

MCDM-23 automates the following simple score calculation procedure. For the three smaller-is-better criteria, the relative score is determined by dividing the numeric score of the scheme being evaluated by the corresponding score of the reference building. For example, if life-cycle cost of the scheme being evaluated is $\$ 60,000$, and the life-cycle cost of the reference building is $\$ 100,000$, the relative score is 0.6 .

For the three bigger-is-better criteria, the scores are first mapped to the smaller-is-better scale and then the process described above is repeated. For example, the architectural quality of the scheme being evaluated is 8 on the 0 -to-10 scale and the architectural quality of the reference building score is 5 (by definition). The 8 converts to a 0.4 . The 5 converts to 1 . The relative score is therefore 0.4 . Scores are displayed on their appropriate axes, making the different scales apparent and avoiding confusion.

MCDM-23 is inherently different than a rating tool such as the GBC tool, LEED, or BREEAM in that it is designed as an aid for decision making prior to final design rather than a means of scoring a completed building. An additional major advantage of the MCDM-23 tool is that it provides a compact and readily understandable means for documenting how decisions were made. This is particularly important in public buildings.

The MCDM-23 program automates calculations, enters results into worksheets, and plots star diagrams for each scheme. The design team then makes their selection based on all information available to them, including the MCDM-23 results.

All intermediate results are displayed on the worksheets and can easily be verified using a calculator. The star diagram is simply a graphic representation of the performance of a scheme 
compared to the reference. Users can quickly compare the performance of each scheme in terms of the main criteria by visual inspection of its star diagram. At this point the star diagrams can be compared side-by-side. If the schemes do not exhibit evident differences, then they are probably not significantly different.

By its nature, preliminary design is an iterative process, cycling through a series of steps until the design meets all criteria. Each cycle typically involves design, evaluation, review, and revision. Both MCDM-23 and ENERGY-10 lend themselves to the evaluation step in each cycle. Again, emphasis must be placed on using the tool quickly so that the evaluations do not hold up the designers unreasonably.

Another use of the tools during preliminary design is performing sensitivity analyses. Because these are computer tools, they can be run repetitively incrementing a single parameter over a range of values. The parameter can then be set to achieve the best performance. In this context, "best" could be the overall score, taking into account all effects captured in the evaluation. Historically, most such optimizations have been done on the basis of minimizing life-cycle cost. Having a tool such as MCDM-23 available can broaden the nature of the optimization, quite possibly leading to significantly different choices.

\section{TESTING THE PROCESS AND TOOLS}

Several of the 12 country groups participating in IEA Task 23 are testing the process described in this paper. Most are using the tools described herein and are getting good results. This is an ongoing activity that will be evaluated to refine the process and tune up the tools. One result will be recommendations of the task regarding tools for trade-off analysis.

A group in the United States Federal Energy Management Program used the process and tools in a rigorous manner during the design of a new weather station for Caribou, Maine, which has a severely cold climate. The design team was particularly impressed that the process led them to discuss all of the six criteria and to agree on priorities. This was something that had not happened previously in their experience. Three design schemes were proposed and evaluated. The MCDM-23 tool provided valuable information at the right time. Two schemes met the previously agreed-upon energy-consumption targets. Ultimately, the best ranking scheme was selected.

\section{CONCLUSIONS}

Widespread application of well-known energyefficiency measures and attention to other factors that affect building sustainability will require streamlining these considerations during the design process. Two vital points in the process have been identified and tools developed that make it practical for a design team to actually carry out the required steps within the time and budget constraints normally imposed.

The stakes are enormous. Energy consumption, the single most important factor affecting sustainability, can typically be reduced by $50 \%$, compared to conventional contemporary construction. This can usually by achieved without increasing the construction cost because of reductions in the installed capacity of heating, ventilating, and airconditioning equipment, which typically accounts for $15 \%$ to $20 \%$ of the initial cost. These reductions often amount to $40 \%$ of the HVAC cost, paying for the added cost of all the other improvements that make the HVAC down sizing possible.

The MCDM process described in this paper ensures that the most important issues that will affect building sustainability are considered equitably as vital decisions are being made during design, where they are most effective and cause no extra expenditure.

\section{ACKNOWLEDGEMENTS}

We wish to thank the 25 members of IEA Task 23 team, who have all contributed in various ways to the development of this process. Anne Grete Hestnes is operating agent of Task 23. The MCDM-23 tool was programmed in Visual Basic by Jun Tanimoto while visiting NREL on a post-doctoral assignment. Funding for the development of both ENERGY-10 and MCDM-23 is from the United States Department of Energy, Drury Crawley, Program Manager.

\section{REFERENCES}

1. Balcomb, J. Douglas (1997), ENERGY-10, A Design Tool Computer Program, proc. Building Simulation '97, International Building Performance Simulation Association, September 8-10, 1997, Prague, Czech Republic

2. Balcomb, J. Douglas (1998), ENERGY-10, Designer Friendly Simulation for Smaller Buildings, Building Performance, Issue 1, Spring 1998, Journal of the Building Environmental Performance Analysis Club, UK. 